\title{
doispontos:
}

\section{Impulso sexual: impulso lúdico e impulso estético}

\author{
Fernanda Silveira Corrêa ${ }^{1}$
}

Resumo: Este artigo analisa o impulso sexual, concebido por Freud, enfatizando sua característica de autoestimulação, mais que de eliminação. Relaciona o impulso sexual com as imagens de movimento, que possibilitaram a Freud, no Projeto de uma Psicologia, pensar o surgimento do pensamento, da linguagem e da ação. Pelo viés de Ferenczi, analisa seu conceito de gestos mágicos (ponto de encontro do impulso sexual e as imagens de movimento) e a ideia de que o impulso sexual é um impulso lúdico. Mostra então a relação do lúdico, da mágica e da arte, em Freud, aproximando-os da concepção estética de Schiller.

Palavras chave: Freud; impulso sexual; imagem de movimento; gesto mágico; impulso lúdico; impulso estético.

Abstract: This article examines the sexual drive, conceived by Freud, emphasizing its characteristic of self-stimulation, rather than elimination. The sexual drive is related to motor images, which enabled Freud, in the Project of Psychology, to think the emergence of thought, speech and action. Considering Ferenczi, the article explores the magic gestures concept (meeting point of sexual drive and motor images) and his idea that the sexual drive is a play drive. Then, the article shows the relation of play, magic and art, in Freud, approaching the aesthetic conception of Schiller.

Keywords: Freud; Sexual drive; motor image; magic gesture; play drive; Aesthetics drive.

\section{INTRODUÇÃO}

Neste artigo analiso a característica de autoestimulação do conceito de impulso (Trieb) sexual, apresentado nos Três ensaios sobre a teoria sexual (Drei Abhandlung zur Sexualtheorie, 1982-2 [1905]), por Sigmund Freud, contrapondo-a a sua característica de eliminação e ressaltando sua importância para a suposição da sublimação e da cultura; relaciono a característica de autoestimulação do impulso sexual com o papel que exercem as imagens de movimento no Projeto de uma psicologia científica (1995 [1895]), imagens que possibilitam a passagem dos processos primários para os secundários; e por fim identifico o impulso sexual com o impulso lúdico, como o chama Ferenczi, e com o impulso estético, aproximando-o de Schiller.

A característica de autoestimulação do impulso sexual, pouco enfatizada pelos comentadores e muitas vezes passada despercebida, parece-me essencial para compreender o conceito de sexualidade perversa, compreender as relações da sexualidade com o desenvolvimento do eu (com o desenvolvimento da linguagem e do pensar teórico) e compreender as relações da sexualidade com a capacidade de figurar suas fantasias e de perceber as formas dos objetos, o que chamarei de sua disposição estética. A aproximação entre o papel exercido pela autoestimulação no desenvolvimento da sexualidade e o papel exercido pelas imagens de movimento no desenvolvimento do eu, no Projeto de uma psicologia, é esclarecida pela concepção de gestos mágicos, apresentado por Ferenczi, um dos principais interlocutores de Freud e tradutor dos Três ensaios sobre a teoria sexual, em $O$ desenvolvimento do sentido da realidade e seus estágios (Stages in 
the development of the sense of reality, 1923 [1913]). Os gestos mágicos são as ações intermediárias entre a sexualidade infantil alucinatória e os processos secundários (o pensar, possibilitado pela linguagem, que leva em conta o princípio da realidade). Ferenczi ainda nos possibilita relacionar o impulso sexual com o impulso lúdico. Voltando a Freud e analisando o que ele concebeu sobre a magia e a arte, podemos compreender, então, o impulso sexual como impulso que as possibilita, podemos considerar o impulso sexual como o impulso que instaura o campo do estético, capaz de figurar a fantasia e a diversidade do mundo - campo do estético como o concebido por Schiller em A educação estética do homem (2011 [1795]).

\section{IMPULSO SEXUAL: ELIMINAÇÃO E AUTOESTIMULAÇÃO}

No segundo dos Três ensaios sobre a teoria sexual (que passarei a chamar de Três ensaios...), Freud caracteriza a sexualidade infantil: perversa, polimorfa e a raiz do impulso sexual. O exemplo típico da manifestação da sexualidade infantil é o chupar: "a ação da criança que chupa é determinada pela busca de um prazer, já vivenciado e agora recordado" (FREUD, 1982-2 [1905], p. 88). Por meio do sugar rítmico, a criança se esforça por renovar suas primeiras experiências de prazer: "o sugar no seio da mãe". É evidente a semelhança da atividade sexual infantil e o processo alucinatório de realização de desejo, descrito no Projeto de uma psicologia (que passarei a chamar de Projeto...), na Interpretação dos sonhos (Die Traumdeutung, 1982-1 [1900]) e em Formulações sobre os dois princípios do funcionamento psíquico (2010-2 [1911]). Apesar de Freud, nos Três ensaios..., não se referir à alucinação, o impulso sexual repete, como no circuito do desejo, as vivências de satisfação. Como o componente essencial das vivências de satisfação é uma percepção, o movimento original do desejo, e, portanto, também do impulso sexual, é investir a imagem recordativa daquela percepção a ponto de torná-la similar à percepção, a ponto de aluciná-la. Podemos dizer que isso vale para todos os impulsos sexuais, para o erotismo oral, mas também para o anal, o genital e para todas as ações prazerosas do corpo que o impulso sexual visa repetir.

A diferença, no entanto, entre a descrição do desejo (que se satisfaz alucinatoriamente) e do impulso sexual, mostra que o impulso sexual possibilitou a suposição da repetição do circuito do desejo independentemente do surgimento da necessidade. Quer dizer, se no Projeto... e na Interpretação dos sonhos, o investimento do circuito de desejo, que acabava em alucinação, ocorria quando o organismo sentia fome, com o conceito de sexualidade tornou-se possível pensar a alucinação mesmo sem a fome. Assim, o impulso sexual é o motor dos processos primários (que conduzem à alucinação) e tem a mesma meta que eles: a eliminação do estímulo. Como é explicitado, em Os instintos [Impulsos] e seus destinos (2010-3 [1915-2]), o impulso tem uma fonte cujo estado de tensão determina uma pressão (Drang), quer dizer, uma porção de atividade que tem como meta a satisfação, isto é, a supressão do estado de tensão na fonte do impulso, o que ocorre por meio do objeto. Como afirma Assoun, a pressão do impulso "se apresenta como um pesado abalo na letargia psíquica, uma notificação do que há a fazer para quem preferia não fazer nada", a pressão traduz uma falta, que "ela é seu sinal" e, "em seguida sua resposta, cujo destino é abolir-se com sua satisfação". Ainda segundo Assoun, esta tendência a abolir-se, suprimir-se, eliminar-se, daria ao impulso uma "força de afirmação ontologicamente precária", pois existe "como intervalo entre uma falta a ser preenchida e uma falta preenchida" (ASSOUN, 1980, p. 107/8).

Devemos notar que esta concepção do impulso sexual possibilita supor, por um lado, que seu objeto é "o que é mais variável no impulso", quer dizer, que seu objeto se deve inteiramente às experiências acidentais de satisfação do sujeito, por outro lado, que o caminho de eliminação do impulso passa pelo objeto e que, uma vez constituído, torna-se o mais invariável - tornam-se invariáveis tanto o caminho como o objeto desejado; o caminho de eliminação será primeiramente percorrido de forma mais intensa, quando o 
reencontro com o objeto se dá de forma alucinatória, ou posteriormente, de forma menos intensa, quando o reencontro ocorre de forma parcial e é auxiliado por caminhos colaterais.

A eliminação por meio do objeto alucinado é a expressão de um psiquismo determinado por suas representações e não pelas necessidades do organismo, um psiquismo determinado pela imaginação e não pela biologia. Trata-se de um organismo que recorda em vez de agir (diante da necessidade, se alucina o objeto que auxilia a satisfação em vez de efetivamente satisfazê-la), trata-se de um aparelho psíquico que coloca a representação do objeto de satisfação (que auxilia a eliminação) no lugar da ação.

Se a concepção de desejo, que se satisfaz alucinatoriamente, afasta o psíquico de sua determinação biológica, o conceito de impulso sexual o faz ainda mais, na medida em que a busca da repetição das experiências de prazer se torna independente do surgimento de uma necessidade, da fome. O impulso sexual torna-se o motor do processo primário, um impulso psíquico determinado apenas por suas vivências de satisfações anteriores.

Se a meta da eliminação é fundamental como caracterização do impulso sexual, encontramos, nos Três ensaios..., outra característica da sexualidade infantil, oposta à eliminação, que chamaremos de autoestimulação, característica fundamental para compreendermos o desenvolvimento sexual do sujeito. Podemos dizer que esta outra característica amplia o intervalo da força de afirmação do impulso sexual, para usar as palavras de Assoun.

A satisfação do impulso sexual, nos Três ensaios..., não implica apenas a sua eliminação, mas também a nova estimulação, "origina-se já na infância junto com o prazer de satisfação um certo montante de tensão sexual” (FREUD, 1982-2 [1905], p.117). O próprio sugar gera uma nova zona erógena, aquela que é sugada, o lábio, a língua, o dedo, ou até o dedão do pé: "a criança não se serve de um objeto estranho para sugar, mas prefere um lugar da própria pele... porque de tal modo, ela cria uma segunda zona erógena, embora de menor valor" (id., p. 89). Assim, do sugar se passa ao manipular e deste à masturbação: "Não raro combina-se com o sugar com deleite o contato friccionado de determinado lugar sensível do corpo, os seios, os genitais externos. Por este caminho muitas crianças vão do chupar sensual à masturbação" (id., p. 87). O movimento rítmico, isto é, a manifestação (motora) da sexualidade não só elimina o impulso, quer dizer, realiza o desejo por meio da alucinação, mas constitui novas zonas erógenas e, portanto, novos desejos. O impulso sexual pode até se manifestar como uma estimulação, apropriada, a fim de alcançar a satisfação: "A meta sexual dos impulsos infantis consiste em provocar a satisfação através da estimulação apropriada" (id, p. 90). É como se o estímulo (a manipulação, por exemplo) proporcionasse a revivência da excitação e, em seguida, da satisfação anteriormente vivida. É essa autoestimulação que dá ao impulso sexual suas características de deslocabilidade, de plasticidade e de flexibilidade.

O desenvolvimento da sexualidade, da sexualidade infantil à função sexual biológica (a sexualidade genital que se realiza no coito), exige o surgimento de um estímulo, de uma tensão sexual. Segundo Freud, qualquer vivência intensa gera excitação sexual: "é possível que nada de significativo aconteça no organismo que não produza seus componentes para a excitação do impulso sexual" (id., p. 109/110). Provavelmente, Freud se refere a uma excitação genital; em alguns casos, ele explicita que se trata de uma excitação no genital, em outros casos, podemos inferi-la, pois ela conduz à masturbação. Na vida adulta, para que ocorra a função sexual biológica, o coito, deve haver uma tensão sexual (excitação) liberada junto à satisfação das zonas erógenas. A função sexual biológica funciona como um télos que, na verdade, nunca será realizado, pois, mesmo que ocorra o coito, ele nunca será inteiramente biológico, sempre estará envolto em fantasias devido a sua origem, nas representações. Mas há uma direção no desenvolvimento da sexualidade, por meio da excitação genital, rumo à realização da função sexual biológica. Assim 
o papel que cabe às zonas erógenas é claro [...] Elas são todas juntas usadas para fornecer por meio de sua estimulação apropriada um certo montante de prazer, a partir do qual provém o aumento da tensão que, de sua parte, tem de introduzir a energia motora necessária para conduzir o ato sexual ao final (id., p. 115).

Prazer de um lado, aumento de excitação, de tensão, do outro: "essas atividades são por um lado ligadas com prazer, por outro, elas aumentam a excitação que deve persistir até alcançar a meta sexual definitiva" (id, p. 60). Por exemplo, quando se olha o objeto sexual, já se está "por um lado, ligada ao prazer, por outro lado, sua consequência é um aumento da excitação sexual ou um provocar da mesma, onde ela falta [...] o aumento ulterior da tensão sexual logo transborda em um nítido desprazer, se não for permitido conduzi-la ao prazer mais distante" (id., p. 114).

A ausência de tensão sexual e, portanto, a presença exclusiva (ou predominante) da satisfação/eliminação caracteriza a sexualidade adulta perversa: "resulta, para o alcance da meta sexual, frequentemente um perigo [...] se, em algum lugar dos processos sexuais preparatórios, o pré-prazer for muito grande e sua parte de tensão muito pequena" (p. 116). Trata-se do caso no qual houve excesso de prazer, portanto, de satisfação e eliminação, na infância, que impediu o surgimento da autoestimulação: "Esse caso prejudicial [...] tem como condição que a zona erógena em questão ou o impulso parcial correspondente tenha contribuído já na vida infantil em uma medida incomum para a obtenção de prazer. [...] Tal é o mecanismo de muitas perversões" (p. 116).

Esta tensão sexual, que conduz à realização da função biológica sexual, e que falta na perversão, pode ser, em algumas passagens, identificada como uma contraforça, como uma barreira que inibe a manifestação sexual perversa e infantil. Se os perversos na infância tiveram muito prazer numa determinada zona erógena e, devido a isso, não desenvolveram a tensão sexual, eles também não desenvolveram as barreiras, as contraforças, que inibem a manifestação sexual. Assim, neles, diante da satisfação oral ou anal, não se desenvolve a repugnância, diante do prazer de ver e ser visto (escopofilia/exibicionismo), não é desenvolvida a vergonha e, diante do prazer sádico/masoquista, não é desenvolvida a dor ou a piedade. Repugnância, vergonha, dor e piedade, por sua vez, serão elementos que levam à relação sexual normal (se estas barreiras faltam ao perverso e são expressão da sexualidade no neurótico, na vida sexual normal, para que ocorra o coito, elas têm de estar presentes, mas não tão intensas como na neurose). Estas barreiras que conduzem à função sexual também podem (e devem) conduzir à sublimação, e por isso são estimuladas pela educação. Assim, a cultura vai ser constituída no espaço entre a sexualidade que se satisfaz na fantasia e sua transformação em função sexual biológica, e seu instrumento será a tensão, o desprazer que o impulso sexual produz, além da sua satisfação/eliminação.

Se a sexualidade perversa possibilitou, por um lado, enquanto impulsos que visam à eliminação, a suposição da prioridade da fantasia, a suposição de um psiquismo determinado pelas impressões das vivências de satisfação e não por funções biológicas, por outro lado, enquanto geradora de tensões, possibilitou a suposição de um organismo que busca o restabelecimento da função biológica sexual (mesmo que nunca a atinja) e que, no caminho deste restabelecimento, pode desviar-se e ser capaz de sublimação.

Em Visão geral das neuroses de transferência (Neuroses de transferência, uma síntese, 1987 [1915-1]), Freud supõe a constituição da sexualidade perversa na história da espécie (na filogênese). Os humanos tiveram de abandonar a função sexual biológica porque sua satisfação envolvia perigos e mantiveram a libido no eu, transformando-a em angústia (como ensina a histeria de angústia), depois, percebendo que a procriação limitava o cuidado com o filho já nascido, evitaram a relação sexual genital, desenvolvendo então a sexualidade perversa (como ensina a histeria de conversão). Portanto, a função sexual procriativa teve de ser abandonada e, em seu lugar, se desenvolveu a sexualidade perversa, que caracteriza a sexualidade original do ser humano, na ontogênese, sua sexualidade infantil, determinada não pela função 
biológica, mas por suas experiências de prazer. Mas, como ensina os Três ensaios..., na ontogênese, a função sexual biológica tem de ser restabelecida. Então, podemos supor que aquilo que fora perdido na filogênese tem de ser resgatado na ontogênese: a sexualidade perversa tem de se tornar função biológica (mesmo que este fim nunca seja atingido). É para se tornar função, na ontogênese, que o impulso sexual terá de ter mais uma característica que não a de buscar eliminação; ele terá de provocar novos estímulos, terá de provocar tensão sexual, desprazer. Assim suposta, será essa tensão, essa autoestimulação, a responsável pela sublimação e, portanto, pelo surgimento da cultura.

\section{IMAGENS DE MOVIMENTO}

Já no Projeto de uma psicologia, apesar da suposição neste texto da tendência do aparelho psíquico à eliminação, existe um mecanismo de estimulação, propiciado pelas imagens de movimento, o qual determina que o pensamento seja parcialmente independente da imagem do objeto desiderativo; que determina, portanto, a passagem dos processos primários para os processos secundários (condição para a sublimação e a cultura). Trata-se de uma característica das imagens de movimento que, além de eliminar estímulos (quantidades), provocam novos estímulos: "todo movimento, através de suas consequências colaterais, dá lugar a novas excitações sensoriais (da pele e dos músculos)” (FREUD, 1995 [1895], p. 32). Quer dizer que, além de eliminar, os movimentos também excitam. É verdade que no Projeto..., para que a excitação provinda do movimento seja percebida e sirva para orientar os movimentos psíquicos, quando o movimento é desejado, será necessária a inibição do movimento reflexo. Aliás é essa a primeira barreira do eu, que possibilitará a inibição da alucinação. Se a vivência de satisfação determinou uma associação entre a fome, a imagem desiderativa e o movimento reflexo (o sugar), o eu "aprende inicialmente que não pode investir nas imagens de movimento de modo que efetue a eliminação enquanto não forem realizadas certas condições do lado da percepção" (id., p. 84). Assim, o eu inibe o movimento, impede a eliminação propiciada pelo movimento, e consegue inibir a alucinação. Será então sensível à percepção, poderá comparar a percepção com a imagem desiderativa e só realizar o movimento quando a imagem percebida for igual à desejada. Se o não investimento da imagem de movimento reflexo auxilia a inibição da alucinação, um investimento moderado das imagens de movimento que se encontram entre a imagem percebida e a desejada possibilita que, depois do processo de pensar (que conduz a percepção à imagem desiderativa), o eu possa realizar o movimento que transforma o percebido no desejado. O exemplo dado por Freud é o do movimento de virar o pescoço. Se entre uma imagem perceptiva, por exemplo, do seio lateral, e a imagem desiderativa, por exemplo, do seio frontal, existir uma imagem de movimento, por exemplo, de virar o pescoço, alcançada a imagem do seio frontal, a imagem de virar o pescoço, pré-investida, será reinvestida, e provocará o movimento. A criança então virará o pescoço e o seio lateral se transformará no seio frontal. Assim, os movimentos acidentais tornam-se ações que transformam o percebido no desejado. Isso é possível porque apesar das imagens de movimento, como também de os movimentos, conduzirem à eliminação, elas realizam uma eliminação quantitativamente menor, ${ }^{2}$ o que propicia que as excitações que elas (como qualquer movimento) provocam se tornem sinais de que o investimento deve se conduzir a elas. Outro exemplo é o do grito, que também, primeiramente reflexo, depois serve para chamar o objeto que auxilia a satisfação, transformando a realidade insatisfatória em uma realidade na qual a presença do objeto proporciona a satisfação.

O pré-investimento da imagem de movimento (possibilitado, então, pela excitação que essa imagem produz) ainda servirá para reconhecer o outro, representá-lo, a partir da identidade do movimento do outro com o próprio movimento. O exemplo dado por Freud é o da compreensão do outro a partir da imagem visual dos movimentos de suas mãos, que coincidem com a recordação de movimentos das próprias mãos. Assim, a imagem de movimento das próprias mãos serve de meta para a imagem visual do 
movimento das mãos do outro. O outro, então, é reconhecido, compreendido, representado (pelo movimento de suas mãos, reconhecido como similar ao movimento das próprias mãos) mesmo não sendo objeto de satisfação ou de dor. No caso, a imagem própria de movimento serve como caminho de eliminação para a percepção do movimento do outro e, ao mesmo tempo, devido às excitações que provoca, fixa a representação do outro. O mesmo mecanismo vale para a representação de todos os objetos externos que se movimentam.

Um mecanismo similar resultará na ampliação dos próprios movimentos, pela imitação dos movimentos dos outros e dos objetos externos em geral. Se a identidade entre o movimento do outro e o meu movimento não for total, é possível ampliar os próprios movimentos (talvez juntando a recordação de dois ou mais movimentos anteriores) e, com isso também, ampliar a capacidade de representar do mundo e de representar as relações do mundo percebido com o desejado (de representar, por meio das imagens de movimento, o pensamento).

Podemos ainda supor que as imagens de movimento possibilitam a atribuição de movimentos (ou melhor, do resultado dos movimentos, como, por exemplo, dos sons, de nomes) àquilo que aparentemente não tem movimento. As imagens de movimento, portanto, serão o fundamento da linguagem. Enquanto imitação dos movimentos dos outros (dos sons emitidos por eles, associados a determinados objetos ou relações de objetos), a ampliação das imagens de movimento referem-se à aquisição da linguagem a partir dos outros e, enquanto imagens de movimento atribuídas aos objetos, referem-se à própria constituição da linguagem, na qual sons, nomes são atribuídos às coisas e às relações entre as coisas.

Assim, as imagens de movimento - com sua dupla função de eliminar e ao mesmo tempo de gerar nova excitação, que serve de sinal - possibilitam a representação de objetos que não os desiderativos e da relação entre os objetos (o pensamento). Representações que são bastante ampliadas pelas imagens de movimento linguísticas. Enfim, elas são o fundamento da linguagem e do pensamento teórico, do processo secundário.

\section{GESTOS MÁGICOS}

Se tomarmos agora como objeto de análise o texto de Ferenczi de 1913, O desenvolvimento do sentido de realidade e seus estágios, texto que Freud considera a única tentativa de utilizar a experiência psicanalítica para compreender o desenvolvimento do eu, ${ }^{3}$ veremos explicitada a relação entre os movimentos próprios (no vocabulário de Ferenczi, os gestos), que conduzem à linguagem e ao pensamento, e a sexualidade infantil.

Ferenczi, neste texto, apresenta distintos períodos do desenvolvimento do eu. O primeiro período é a onipotência incondicional, quando a criança vive ainda no ventre materno e todas suas necessidades são satisfeitas incondicionalmente. O segundo período, denominado de onipotência alucinatória mágica, corresponde ao desejo cuja realização é a alucinação, como foi descrito por Freud no Projeto..., no capítulo VII da Interpretação dos sonhos (1982-1 [1900], e em Formulações sobre os dois princípios do funcionamento psíquico (2010-2 [1911]). Nesse último texto, esse período é reconhecido como uma fase do eu: o eu prazer.

O terceiro período, suposto por Ferenczi, é o da onipotência com a ajuda de gestos mágicos. Os gestos descritos por Ferenczi, que a criança, primeiro, acredita que são mágicos e que, no período seguinte, servirão para representar o mundo, curiosamente são as manifestações da sexualidade infantil, o exemplo típico: o sugar. Este gesto é percebido pelo adulto que proporciona a satisfação à criança. Para a criança, 
no entanto, é um gesto mágico, que por si só provoca a satisfação. A manifestação sexual, portanto, pode ser compreendida como gesto e ter o significado de ação que realiza o desejo.

No estágio posterior, denominado pensamentos e palavras mágicas, os gestos da criança, "as funções de excreção e atividades como chupar, comer e tocar as zonas erógenas”, servirão para reconhecer os processos do mundo externo semelhantes ("a criança vê no mundo reproduções de sua corporalidade"). A partir disso, a criança aprende então a "figurar por meio de seu corpo toda a diversidade do mundo externo". Aos poucos, o simbolismo gestual é então substituído pelo simbolismo verbal. O reconhecimento do outro a partir dos próprios movimentos já fora, como vimos, descrito por Freud no Projeto.... Podemos, então, dizer que figuramos por meio de nossos movimentos todas as diversidades do mundo, pois reconhecemos uma identidade entre os movimentos dos objetos externos e os nossos, ou atribuímos um movimento próprio (um som, isto é, um nome) aos diversos aspectos do mundo. No Projeto..., no entanto, ainda não havia o conceito de sexualidade infantil e os movimentos que serviam para representar a diversidade do mundo estavam distantes do desejo (o sugar que estava próximo do objeto desiderativo alucinado, não servia para representar o mundo e não devia ser investido até que surgisse a percepção do objeto desiderativo, quer dizer, ele não servia ao pensar). Ferenczi, no entanto, explicita que as imagens de movimento, tão importantes para o desenvolvimento do eu, quer dizer, para o desenvolvimento da linguagem e dos processos secundários, nada mais são que expressão da sexualidade infantil; são os movimentos de sugar, os movimentos relacionados à função de excreção, de tocar as zonas erógenas, movimentos muito bem caracterizados por Freud, nos Três ensaios... Podemos dizer que, com Ferenczi, a sexualidade infantil é explicitada como fundamento dos processos secundários. A sexualidade infantil, então, não representa apenas o processo primário (alucinatório), mas é também a condição para a inibição do processo primário e a constituição de processos independentes das representações dos objetos desiderativos.

Olhando dessa forma para a sexualidade infantil, para o impulso sexual infantil, a característica de autoestimulação, que vimos presente nos Três ensaios..., torna-se mais fundamental. Podemos dizer que é porque o impulso sexual se desloca, porque ele não repete sempre a mesma vivência de prazer, mas se expande para outras zonas erógenas e para outros movimentos (do sugar, para o manipular, para o reter, para o ver, para o masturbar-se e, podemos completar, para o emitir sons) que ele cumprirá este papel de representar, figurar as diversidades do mundo.

\section{IMPULSO LÚDICO}

Vejamos ainda outra compreensão desta característica do impulso sexual de gerar excitação, além de eliminá-la. De acordo com Ferenczi, em Ensaio sobre a teoria da genitalidade: Thalassa, (1990 [1923]) - ensaio posterior à sua tradução dos Três ensaios..., que foi realizada em um período de intensa correspondência com Freud -, os impulsos eróticos, sexuais, correspondem, em parte, aos impulsos lúdicos (Spieltrieben). Trata-se de impulsos que simulam uma tensão, um desprazer, anteriormente vivido, para desfrutar da repetição de sua superação, para desfrutar da satisfação. Segundo Ferenczi, o coito, por exemplo, visa restituir uma situação sem estímulo (similar ao ventre materno), mas o faz reproduzindo as situações traumáticas: "supomos que o coito representa não só o retorno - meio fantasiado, meio real - ao ventre materno, mas traduz também, por seus sintomas, a angústia do nascimento e a vitória alcançada contra ela, ou seja, o feliz desfecho do nascimento" (FERENCZI, 1990 [1923], p. 49/50). O coito então não só busca retornar a um momento em que todo estímulo é eliminado (quando se estava no ventre materno), mas também repete um aumento de excitação, a angústia despertada no trauma do nascimento, e seu desfecho final (a eliminação da excitação). A angústia repetida é, no entanto, reproduzida em um grau controlável e parece servir ao feliz desfecho. Essa tendência corresponde ao impulso lúdico. Para 
descrever este impulso, Ferenczi recorre às ideias apresentadas por Freud em Além do princípio do prazer (2010-1 [1920]):

Freud explica certos sintomas da neurose traumática e também algumas particularidades do jogo da criança pela compulsão a descarregar progressivamente, em pequenas doses multiplicadas, as quantidades de excitação não liquidadas e que sua intensidade não permite liquidar "em bloco" (FERENCZI, 1990 [1923], p. 50).

O jogo da repetição da angústia e do feliz desfecho - o jogo do Fort-da em que a criança, jogando seu carretel, representa a vivência do afastamento da mãe e, puxando-o de volta, representa seu feliz desfecho, o retorno da mãe - gera excitações, angústias, para então descarregá-las em pequenas doses. O mesmo, segundo Ferenczi, ocorre no coito:

Nós também consideramos que o coito representa a descarga parcial do "efeito choque" do trauma de nascimento que ainda não foi liquidado; mas, ao mesmo tempo, também vemos aí um jogo ou, mais exatamente, uma festa comemorativa, celebrando o feliz desfecho de uma situação difícil (id., p. 50).

Assim como no jogo, no coito se repete a angústia provocada por uma situação traumática, a maior delas, o nascimento, para repetir o feliz desfecho.

O impulso sexual, lúdico, repete o desprazer, em uma dosagem conhecida, para, em certa medida, superá-lo, nisto está a fruição:

É nesse caráter lúdico que vemos o elemento de pura fruição da satisfação genital [...] no que se refere aos impulsos lúdicos, entre os quais podemos também classificar, num certo sentido, os impulsos eróticos, é o próprio impulso de desfrutar da interrupção de perturbações. O que caracteriza, portanto, a tendência lúdica e o erotismo é que [...] o desprazer só é autorizado de acordo com uma dosagem conhecida e medida; em segundo lugar, as modalidades defensivas são previstas de antemão e, com frequência até um grau excessivo (id., p. 51/2).

No caso do impulso lúdico e erótico, portanto, diferente dos outros impulsos, ele próprio suscita um desprazer com o intuito de desfrutar de sua interrupção e o desprazer só é permitido em certa medida. Ferenczi exemplifica:

Eu estaria tentado a considerar a fome, por exemplo, um impulso simples que se destina a fazer cessar a sensação de desprazer provocada pela privação física, e o apetite como seu paralelo erótico; pois que, no caso do apetite, essa pequena privação somada à garantia de uma satisfação correspondente deve, antes, ser levada a conta de um prazer preliminar (id., p. 52).

Assim, a sexualidade de certa forma brinca com o perigo: "O coito recorda aqueles melodramas em que as nuvens ameaçadoras se acumulam como numa verdadeira tragédia, mas em que se tem sempre a impressão de que 'no final, tudo acabará bem'” (id., p. 53).

O coito, para Ferenczi, é uma repetição lúdica da lembrança de ter sido libertado do desprazer, de ter conseguido sobreviver ao perigo envolvido no nascimento e da alegria de existir mesmo fora do corpo da mãe. As situações de perigo são reproduzidas para em seguida serem afastadas. Algo similar parece ocorrer com a sexualidade infantil, que reproduz a estimulação para alcançar a eliminação. Assim, a sexualidade simula a fome, a necessidade de evacuação, o frio e suas superações: a amamentação, a defecação, a micção, o aquecimento. Repete o surgimento do estímulo e sua eliminação.

Podemos, então, dizer que se a meta final do impulso sexual é a alucinação (o restabelecimento da vivência de satisfação, por meio do objeto desiderativo), como é o retorno alucinatório ao ventre materno na 
teoria do coito, de Ferenczi, que é alcançado repetindo o desprazer que a antecedeu. Antes da eliminação, é suposta a repetição da estimulação. Assim, o impulso sexual, antes de se caracterizar como eliminação, caracteriza-se como autoestimulação, o que abre espaço para os estímulos percorrerem outros caminhos antes da eliminação: joga-se, brinca-se, figura-se a diversidade do mundo, antes da eliminação. Trata-se do campo da cultura e da sublimação. Se vimos que este campo acontecia entre a sexualidade perversa e a função biológica (que, se fosse possível de ser realizado, representaria o máximo de eliminação, já que não manteria nada na fantasia), agora vemos que ele ocorre na própria satisfação do impulso sexual, que, antes de alucinar, simula o desprazer que foi satisfeito na alucinação.

Mas não só o desprazer é repetido nas manifestações sexuais que antecedem a satisfação (alucinada ou recordada). Os próprios movimentos, naquilo que contêm de autoestimulação, tornam-se em si prazerosos, meta, e não meio para a satisfação. Em Totem e tabu (2012 [1913]), Freud descreve o jogo, o brincar da criança, como uma alucinação motora, distinta da alucinação sensorial. O jogo da criança, assim como a magia nos povos primitivos, desloca o acento psíquico do motivo da ação (da alucinação) para os meios, quer dizer, para a própria ação (que é o meio de alcançar a alucinação).

\footnotetext{
a criança, inicialmente, satisfaz seus desejos de forma alucinatória ... Para o homem primitivo adulto, há um outro caminho. No seu desejo prende-se um impulso [Impuls] motor, a vontade, e esta - que depois, a serviço da satisfação do desejo, mudará a face da Terra - é agora usada para apresentar a satisfação, de modo que possa vivenciá-la, por assim dizer, através de alucinações motoras. Uma tal apresentação do desejo satisfeito é comparável à brincadeira [Spiel] das crianças, que nelas substitui a técnica puramente sensorial de satisfação. ... Com o tempo, o acento psíquico desloca-se dos motivos da ação mágica para seus meios, para a própria ação. Talvez diríamos mais corretamente que apenas nesses meios tornam-se a ele evidentes a superestimação de seus atos psíquicos (FREUD, 2012 [1913], p. 134).
}

$\mathrm{Na}$ alucinação motora é atribuída grande importância às próprias ações, aos próprios movimentos. É como se, aos poucos, o objeto de desejo alucinado (o motivo do desejo) fosse perdendo sua importância e cedendo lugar para a ação que se liga a ele (os meios). Por exemplo: mais importante que a chuva alucinada será a realização da ação que a imita; na criança, mais importante que alucinar o seio será imitar a ação do seio sobre a boca. Trata-se, portanto, daquele momento em que os gestos ganham uma importância independente da vivência de satisfação. A autoestimulação, mesmo visando à satisfação (à eliminação), possibilita essa independência.

\section{IMPULSO ESTÉTICO}

O campo da cultura no qual ainda se preserva a alucinação motora (onipotência por meio do impulso motor) é a arte:

Apenas em uma área em nossa cultura, a "onipotência dos pensamentos" também foi conservada, na área da arte. Unicamente na arte ainda sucede que um homem consumido por desejos faça algo semelhante à satisfação, e que esse jogo provoque - graças à ilusão artística - efeitos de afeto como se fosse algo real. Com direito, se fala do feitiço da arte e se compara o artista a um feiticeiro. [...] A arte [...] esteve originalmente a serviço de tendências que hoje estão em grande parte extintas. Entre elas, pode-se supor várias intenções mágicas (id., p. 142/3).

$\mathrm{O}$ artista, sem o querer, acaba provocando efeitos na realidade. Estes efeitos devem-se principalmente ao reconhecimento, por parte dos outros, do valor da obra de arte produzida. No entanto, a própria valorização dos próprios gestos e pensamentos, pelo artista, parece, por si só, possibilitar uma compreensão da realidade e, dessa forma, um certo domínio sobre a mesma. A primeira compreensão do mundo é artística e é mimética, pois a magia implica a cópia das ações do que é desejado. 
Em Formulações sobre os dois princípios (2010-2 [1911]), Freud considera a arte como passagem do princípio do prazer para o de realidade, quando se figura a fantasia em um tipo de realidade:

A arte consegue por um caminho peculiar uma reconciliação entre os dois princípios [princípio do prazer e da realidade]. $\mathrm{O}$ artista é originalmente um homem que se afasta da realidade, pois ele não pode aceitar a renúncia à satisfação dos instintos [impulsos] que ela a princípio exige, e consente na vida de fantasia seus desejos eróticos e ambiciosos. Ele encontra, porém, o caminho de volta deste mundo de fantasia para a realidade, na medida em que, devido a dons especiais, ele figura suas fantasias em um novo tipo de realidade, que são valorizadas pelos homens como reflexos preciosos do real (FREUD, 2010-2 (1911), p. 117/8).

Figurar as fantasias corresponde à alucinação motora, à onipotência dos gestos. Os gestos, portanto, são o intermédio entre o puro movimento da sexualidade, como o sugar, que estabelece a alucinação, e a ação que efetivamente transforma o mundo levando em conta a realidade, ou, antes disso, as imagens de movimento ou linguísticas que permitem a representação do mundo, independentemente do desejo.

Assim, se os movimentos que manifestam a sexualidade (primeiro reflexos, intensificadores da alucinação, e, depois, gestos, na medida em que transformam a realidade) e que são expressão da fantasia de restabelecimento da vivência de satisfação, por meio do objeto desiderativo alucinado, ganharem o acento psíquico anteriormente dado ao objeto alucinado da fantasia, o aparelho anteriormente incapaz de realizar a ação específica (ou de realizar a função biológica) restabelece a ação, não mais a ação que satisfaz o instinto biológico, mas que busca estabelecer uma realidade desejada.

Vimos que o impulso sexual se caracteriza pela deslocabilidade, mas, podemos supor, que antes de se deslocar pelas zonas erógenas, pelas próprias ações (sugar, manipular, masturbar-se), ele se desloca da alucinação para o movimento, o que inibe a alucinação e restabelece uma nova ação, não mais biológica, capaz de representar o mundo e de transformar a realidade percebida na desejada.

Este deslocamento da alucinação sensível para a motora, da onipotência alucinatória para a onipotência do gesto, da satisfação na representação para o investimento da imagem de movimento, caracteriza-se como uma figuração da fantasia, antes satisfeita na alucinação. Como se a fantasia, que visava repetir a vivência de satisfação, realizada na alucinação do objeto desiderativo, agora pudesse ser encenada. Essa encenação, por sua vez, inibe a alucinação, e expande as representações do eu, as representações perceptivas e as de movimento. Este espaço lúdico, da criança que brinca em vez de alucinar, do primitivo que desenvolve a magia, estabelecendo uma ação sobre a realidade, corresponde ao espaço estético, no qual os desejos e as fantasias são figurados. Como em Schiller, o impulso estético estabelece o reino do jogo, no qual "se toma posse de si mesmo":

a forma começa a tomar posse dele mesmo... transformando também o homem interno. O salto desregrado da alegria torna-se dança, o gesto informe torna-se movimento gracioso e harmônico; os sons desordenados dos sentimentos desdobram-se, obedecem ao compasso e ordenam-se em canto (SCHILLER, 2011 [1795], p. 132).

Trata-se da passagem do movimento reflexo, acidental, para o gesto. Se essa passagem corresponde à figuração da fantasia, é entre um e outro que se constitui a fantasia, na qual o movimento reflexo se insere, já que tem como primeira meta conduzir à alucinação do objeto desiderativo. O deslocamento do acento psíquico da alucinação do objeto para o movimento, por sua vez, significou a passagem da pura fantasia (cuja realização é alucinada) para a figuração desta fantasia; os gestos, a dança, o canto, encenam os anseios angustiosos pelos objetos e, por meio dos movimentos, seu encontro.

Por outro lado, a capacidade de ser sensível às formas do mundo, de figurar a diversidade do mundo, foi suposta como a origem da humanidade, por Schiller. Trata-se novamente da disposição estética, que está 
além da satisfação da necessidade (e por isso é desinteressada e livre) e que corresponde às tentativas de embelezamento, que dá preferência à forma e à aparência:

Onde encontramos os indícios de uma apreciação desinteressada e livre da pura aparência, podemos suspeitar essa reviravolta em sua natureza e o verdadeiro início de sua humanidade. Encontramos indícios dessa espécie já em suas toscas tentativas de embelezamento de sua existência, mesmo com risco de prejudicar o conteúdo sensível. Tão logo comece a preferir a forma à matéria e postergue a realidade em favor da aparência [...], seu círculo animal se abre, e ele se encontra numa via que não termina (id., p. 129).

Segundo Schiller, o campo do jogo não é o campo da privação, da necessidade, da adaptação ou da reação, mas é o campo da liberdade, da expressão da força, do jogo sem utilidade, da ação:

Mesmo ao irracional a natureza deu mais que a simples privação, lançando na obscura vida animal uma centelha de liberdade. Quando o leão não sente fome e não há outra fera a desafí-lo, a força ociosa cria um objeto; o bramido cheio de ânimo ecoa no deserto, e, num dispêndio sem finalidade, a força vigorosa compraz-se em si mesma. [...] O animal trabalha quando uma privação é o móbil de sua atividade e joga quando a profusão de força é este móbil, quando a vida abundante instiga-se à atividade. Mesmo na natureza inanimada encontramos um tal luxo de forças e uma tal variedade de determinações que poderiam ser chamadas de jogo no sentido material. São inúmeras, numa árvore, as mudas que irão murchar inúteis; as raízes, os ramos, as folhas são em número muito maior que o necessário à preservação do indivíduo e da espécie. O que a árvore por plenitude perdulária devolve, sem ter usado ou fruído, ao reino dos elementos, poderá ser dissipado, pelos viventes em alegre movimento (id., p. 130).

A abundância existe na natureza, mas em poucos momentos ela é fruída pelos outros seres vivos. $O$ leão brinca, joga quando brame sem ter necessidade disso (quando não é pressionado nem pela fome nem pelo perigo). Mas o homem, mais que qualquer outro animal, frui em alegres movimentos da abundância das forças contidas na natureza. Ele age, predominantemente, movido não pela privação, mas pela profusão de forças.

Para Freud, a humanidade se caracteriza pela instituição do campo da imaginação, da fantasia, mas também, como em Schiller, pela capacidade de fruir da forma do objeto, quer dizer, pela capacidade de ser sensível aos objetos. Como vimos o reconhecimento do outro, por meio da semelhança do movimento do outro com o próprio movimento, causa prazer, fruição, e de certa forma, domínio do objeto.

Em Freud, é o prazer no movimento (possibilitado pela sexualidade perversa) que possibilita que a forma do objeto (seu movimento) seja reconhecida. O reconhecido no objeto ganha um novo valor, o valor formal, além do material, que passa a ser representado. Neste momento, então, o homem passa a ser sensível ao objeto (a sua aparência), em vez de necessitar dele.

Este homem estético não só antecipa o gozo na imaginação (como em Freud, não só se satisfaz alucinando suas representações), mas também incorpora a forma à sua fruição, como afirma Schiller:

Enquanto apenas acumula reservas para o seu futuro e antecipa o seu gozo na imaginação, ele ultrapassa na verdade o momento presente, mas não ultrapassa o tempo em geral; frui mais, porém, não de outra maneira. Quando, entretanto, incorporar a forma a sua fruição, atentando para as formas dos objetos que lhe satisfazem os desejos, ele terá não só aumentado sua fruição em extensão e grau, mas também a terá enobrecido segundo a espécie (ibid.).

Figuração da fantasia e figuração da diversidade do mundo, portanto, são constituintes do campo estético e, em Freud, produto da sexualidade humana, produto do impulso sexual, que não visa apenas a sua eliminação, mas caracteriza-se pela excitação, por um movimento de autoestimulação. 
Se voltarmos ao texto Visão geral das neuroses de transferência (Freud, 1987 [1915-1]), na terceira fase, depois da constituição da sexualidade perversa (que ocorreu na segunda fase), a sexualidade passa a se satisfazer no domínio sobre o mundo, no domínio possibilitado pela linguagem e pela inteligência. Trata-se, portanto, do deslocamento da alucinação sensorial para a alucinação motora, para ação. Ação que fora perdida na primeira fase, mas que agora é resgatada tendo como meta as representações que satisfizeram o impulso na segunda fase (os objetos desiderativos), ação que não é adaptativa, mas expressão de uma profusão de forças potencializadas pelas fantasias. Neste sentido, a satisfação do impulso sexual pode ser considerada afirmação de si, vontade de poder. Assim compreendemos a psicologia do indivíduo, do pai primitivo, que satisfaz livremente seus impulsos sexuais e que Freud, em Psicologia das massas e análise do eu (Freud, 2011 [1921]), comparou com o além do homem de Nietzsche. Consideramos que Freud refere-se ao tipo psicológico do nobre, do senhor, do forte, de Nietzsche, um tipo ativo e afirmativo, que cria, a partir de si mesmo, o mundo dos valores e que marca cada coisa e acontecimento com um som, como que se apropriando dos mesmos. O indivíduo, o pai primitivo, é aquele que satisfaz livremente seus impulsos sexuais, dotando de forma o mundo e si mesmo, e, neste sentido, constituindo o campo da estética. Não sem ter contra a essa afirmação do impulso sexual perverso, primeiro, a necessidade de restituir a função sexual biológica, e, segundo, a psicologia dos filhos, da coletividade, que fará severas exigências contra a expressão do impulso sexual, contra seu aspecto agressivo. A agressividade terá de torna-se desejo de submissão, transformar-se em seu oposto, no amor fraterno, e por fim voltar-se contra o próprio eu, contra o próprio impulso. A civilização, no entanto, requer não só a repressão do impulso, mas também sua capacidade de sublimação e criação, sua característica lúdica e estética.

\section{BIBLIOGRAFIA}

ASSOUN, Paul-Laurent. (1989). Freud e Nietzsche, semelhanças e dessemelhanças. São Paulo: Brasiliense.

FERENCZI, Sandor. (1923. [1913]). Stages in the development of the sense of reality. Sex in Psychoanalysis. New York, Basic Books, inc. Publishers.

tins Fontes.

(1990 [1923]). Thalassa: ensaio sobre a teoria da genitalidade. São Paulo: Mar-

FREUD, Sigmund. (1982-1 [1900]). Die Traumdeutung. Studienausgabe. Band II. Frankfurt am Main: Fischer Taschenbuch Verlag.

(1982-2 [1905]). Drei Abhandlung zur Sexualtheorie. Studienausgabe. Band V. Frankfurt am Main: Fischer Taschenbuch Verlag.

(1987 [1915-1]). Neuroses de transferência: uma síntese (manuscrito recém-descoberto). Versão bilíngue. Rio de Janeiro: Imago.

(1995 [1895]). Projeto de uma psicologia. Obras isoladas de Freud. Tradução Osmyr Faria Gabbi Jr. Rio de Janeiro: Imago.

(2010-1 [1920]). Além do princípio do prazer. Obras completas. Vol. 14. Tradução Paulo César de Souza. São Paulo: Companhia das Letras.

(2010-2 [1911]). Formulação sobre os dois princípios do funcionamento psí- 
quico. Obras completas. Vol. 10. Tradução Paulo César de Souza. São Paulo: Companhia das Letras.

(2010-3 [1915-2]). Os instintos e seus destinos. Obras completas. Vol. 12. Tradução Paulo César de Souza. São Paulo: Companhia das Letras.

(2011 [1921]). Psicologia das massas e análise do eu. Obras completas. Vol. 15.

Tradução Paulo César de Souza. São Paulo: Companhia das Letras.

(2012 [1913]) Totem e tabu. Obras completas. Vol. 11. Tradução Paulo César de Souza. São Paulo: Companhia das letras.

NIETZSCHE, Friedrich. (1998 [1887]). Genealogia da moral. São Paulo: Companhia das Letras.

SCHILLER, Friedrich (2011 [1795]). A educação estética do homem, numa série de cartas. São Paulo: Iluminuras.

\section{NOTAS}

1. Doutora e mestre em Filosofia pela Unicamp, psicóloga formada pela PUC-SP, autora do livro Filogênese na metapsicologia freudiana (ed. Unicamp, 2016), professora universitária e psicanalista.

2. "Efetivamente não se move ao representar-se uma imagem de movimento. Mas o representar e o mover são apenas quantitativamente distintos” (FREUD, 1995 [1895], p. 32).

3. Cf. Visão Geral das neuroses de transferência. 